\title{
Denis Diderot, Contra el colonialismo y las tiranías. Contribuciones políticas a la "Historia de las dos Indias", Estudio introductorio, traducción y notas de Roberto R. Aramayo
}

(2020) Plaza y Valdés Madrid, $248 \mathrm{pp}$.

Julio Seoane Pinilla

Universidad de Alcalá

ORCID ID 0000-0001-7290-0129

julio.seoane@uah.es

\section{Cita recomendada:}

Seoane Pinilla, J. (2021). Denis Diderot, Contra el colonialismo y las tiranías. Contribuciones políticas a la 'Historia de las dos Indias', Estudio introductorio, traducción y notas de Roberto R. Aramayo. Eunomía. Revista en Cultura de la Legalidad, 20, pp. 487-491. doi: https://doi.org/10.20318/eunomia.2021.6091

Me voy a permitir la licencia de imitar el espíritu que de alguna manera empapa esta obrita de Diderot y por ello voy a comenzar in media res y ser algo desordenado. ¿Desordenado? Me explicaré más tarde, por el momento déjeseme iniciar esta reseña comentando con quien nos hayamos aquí. Y no, no voy a hacer una introducción a Diderot que sería abundar en lo ya muy conocido, sino simplemente intentaré tratar de dibujar la persona que aparece a través de las líneas del libro aquí reseñado para después dedicarme a hablar del libro propiamente dicho.

Para empezar, y al hilo del subtítulo del libro, tenemos a un ilustrado que se muestra frente a la esclavitud y al colonialismo. No era ello común en el XVIII -aunque tampoco era raro- y debemos poner en el haber de Diderot el mérito de esta doble protesta: contra la esclavitud a la cual considera un atentado a la dignidad humana y a todos los derechos que por naturaleza le corresponden; y contra el deseo europeo de ver Europa por todos lados. Si lo primero es relevante y se puede unir a muchos respetables pensadores que clamaron contra un sistema esclavista que si bien era 
inigualable a la hora de explotar las riquezas de las colonias también era en la misma medida insultante para la humanidad, lo segundo merece alguna consideración más. Algún detalle que aleje a Diderot del mainstream de autores antiesclavistas más o menos conocidos, más o menos orillados, que hoy gustamos de barajar en nuestros juegos. $Y$ ese detalle es «sencillamente» el hecho de percibir que cuando se mira al mundo con las orejeras europeas uno ni percibe el mundo ni percibe realmente a Europa. Casi como en un precursor de las propuestas poscoloniales, Diderot se da cuenta de que nuestra visión de los salvajes dice mucho de nosotros. Sobre todo, de nuestra incapacidad para reconocer que la naturaleza humana es mucho más multiforme y llena de promesas y posibilidades de lo que la llustración -nuestra modernidad-generalmente percibió. Ver Europa en las colonias o en las nuevas tierras y lejanos mares de los que hacía tiempo se daban noticia es una buena manera de no saber ver lo complejo que es el mundo -le monde, i.e., la Europa civilizada-.

El indio, y aquí es cierto que no se debe esperar una visión que ni siquiera hoy tenemos, es visto por Diderot con los moldes de su época: un espíritu estoico que soporta las desgracias sin una queja, que no tiene grandes pasiones y que se conforma con bien poco. Casi en un reflejo del buen salvaje rousseauniano, el primitivo aparece en esta obrita como suele aparecer en el mundo ilustrado, a saber, como alguien ajeno a los vicios modernos porque no tiene ninguna necesidad más allá de la alimentación y la procreación, es decir, que no ha conocido los lujos que hace débiles a los modernos civilizados -y en la discusión sobre el lujo, lo que nos hace débiles, lo que hoy llamamos consumo, en buena parte se puede dirimir el doble camino que tomó la llustración en la forja del mundo moderno-. Pero hay una diferencia considerable en la apreciación del salvaje que Diderot muestra en estas páginas que, repito, siguen los cánones de su época; una diferencia que marca una clara diferencia entre Diderot y sus coetáneos pues generalmente este espíritu estoico, claro reflejo del mito de Esparta, se muestra como un lugar ya inalcanzable que de alguna manera sirve para fundamentar el orden que la modernidad constituía; un orden donde puesto que tal universo original no era ya alcanzable se intentaba llegar a cotas similares de felicidad a través de una legislación completamente nueva $y$, por supuesto, diferente a la del buen salvaje que o bien recogiera aquel mundo como en el caso de Rousseau, o bien, como sucedió con Hume o A. Smith, reconociera que aún más débil y enfermiza nuestra moderna civilización era menos cruel y más «humana». Por el contrario, aquí Diderot nos acerca una visión del otro como alguien que no nos enseña, que no nos muestra cómo es la naturaleza humana, sino que sencillamente vive de un modo diferente. Y quizá lo que aprendemos con él no es tanto el fundamento del mundo que queremos tener, sino sencillamente el valor de la diferencia que, aunque no siempre es entendida, no por ello debe ser minusvalorada. No siempre es así, por supuesto, y en varias ocasiones podemos ser testigos de las imprecaciones de Diderot ante la brutalidad y salvajismo de algunas hordas y tribus primitivas a las que se toma por salvajes y bárbaras sin ninguna contemplación, pero siempre son calificadas así no de un modo imperativo, sino porque en comparación con el mundo que se quiere entrever por Diderot quedan muy fuera de lugar.

Y ligado a esta consideración del salvaje -que repito: no es el origen de un contrato social, sino aquel que está ahí y nos recuerda que lo diferente existe- está el hecho de que Diderot apueste contra el colonialismo. En el caso de las colonias de América del Norte, es bien explícito clamando contra el hecho de que las libertades europeas se restringen en las colonias - «os aterroriza el hobbesianismo en vuestra vecindad, pero sin embargo en la distancia ponéis en práctica este funesto sistema que hace de la fuerza la ley suprema» (Diderot, 2020, p. 163)-, mostrando la evidencia de que no por llegar a una tierra allende el mar y poner una placa tal tierra pasa inmediatamente a la propiedad de quien paga la expedición, o proponiendo que 
el mejor modo de gobernar las colonias no es subyugándolas sino haciendo un nuevo pueblo - «tales serían los felices efectos que produciría en una colonia floreciente el atractivo del más poderoso de los sentidos. Nada de armas ni soldados, sino muchas jóvenes para los hombres y muchos jóvenes para las mujeres» (p. 159) -. Todo ello le lleva a clamar por la independencia de las colonias de América del Norte con militancia y fervor.

Pero si tenemos a un pensador contra la esclavitud y el colonialismo, también se dibuja a lo largo del texto un convencimiento, no sé si ilustrado o liberal o ambas cosas a la vez, de que es el comercio entre los pueblos y la propiedad privada el primer elemento que protege tanto el progreso y la paz en nuestros gobiernos como el reconocimiento de lo diferente. La apuesta de Diderot aquí no es extraña en su siglo y no son pocos los autores que están convencidos de que si es posible una paz entre las naciones está ha de venir por los intereses comerciales, por la necesidad de establecer intercambios que favorezcan la riqueza de la nación - «una guerra en medio de diferentes naciones comerciantes es un incendio perjudicial para todas» ( $p$. 29) - y todo ello tiene que ver con la necesidad de establecer un derecho a la propiedad como garantía para conseguir una sociedad libre - «un pueblo sabio no se permitirá ningún atentado contra la propiedad ni contra la libertad» (p. 165) - . A veces parece que estamos ante un autor liberal à la Mill - ello es más evidente en su defensa de la libertad de prensa que «produce sin duda inconvenientes, pero son tan frívolos y efímeros en comparación con los beneficios que no me molestaré en detenerme aquí» (p. 100) - y para aclarar realmente la postura de Diderot es el momento de ordenar un poco mi reseña y de la mano del editor de la misma, vamos a ver qué es realmente lo que tenemos aquí, qué ideas se proponen, qué de interesante podemos adquirir por el precio de este libro.

A lo largo de la introducción el editor de la obra hace explícito su convencimiento de que Diderot aún sin tener un tratado político, sí que es cierto que acuñó la idea de voluntad general antes que Rousseau, que trabajó con una idea de ley similar a la de Montesquieu, que propuso nociones sobre el derecho natural, la ciudadanía, etc., a la par, sino antes, que los autores que generalmente estudiamos como teóricos políticos en relación a semejantes asuntos. Es cierto que tal no lo hizo de modo sistemático, pero el editor apuesta por que en diferentes obras -y principalmente en esta recopilación que nos proporciona- se puede rescatar un completo compendio de conceptos políticos que aúpan a Diderot al nivel de los tradicionales teóricos de la modernidad política. Ello puede ser, no me cabe duda, pero hay que decir que Diderot nos ofrece sus reflexiones políticas como lo haría un viejo sabio contando batallitas, con cierto desorden, uniendo unos temas con otros que no tienen nada que ver. Ello se puede ver con claridad en el capítulo VI de este libro, el titulado "Del comercio» donde, para sorpresa del lector, no se habla del comercio y lo que se ofrece es una mezcolanza de comentarios sobre México, Canadá, los hospitales, el asilo, algunos comentarios sobre los negros y en su apartado final que se titula "Comercio de la Indias» se dedica a hablar de los filósofos. Debo diferir del editor, aunque ciertamente en no mucho; estoy con él en su apuesta por tomar a Diderot como un pensador valioso en relación -también- con los conceptos políticos que ofreció -que nos ofrece-, pero el modo en como los expone -al menos en este libro y sobre todo en los capítulos finales- es con poco orden, hablando de todo de manera indistinta. El editor no se ha preocupado de cuidar la ordenación sistemática de las intervenciones de Diderot, ha sido fiel a su desorden y en no pocas ocasiones no sabemos si lo que leemos es un capítulo de un capítulo o un parágrafo de un capítulo de un capítulo y ni siquiera es claro qué tiene que ver lo que se deja leer con el título que lo encabezaba. Personalmente creo que está por demostrar que la mezcolanza expositiva sea un demérito y no me importa perderme en los textos cuando son interesantes como los que aquí se ofrecen, pero al lector 
más ordenado le debo advertir que muchas veces no queda claro qué es lo que se quiere decir «con prioridad». Aunque, qué duda cabe, el texto se deja empapar con todo lo que dice.

Y ¿qué es lo que dice? Dejando aparte la mezcolanza de temas y el deambular por cuestiones -que en no pocas ocasiones recuerda al obrar de Montaigne- a este respecto el editor está más que acertado: Diderot aquí oficia de pensador político. Dice de la Ley que «no es nada si no es una espada que se pasea indistintamente sobre todas las cabezas» (p. 99) de modo que al llegar a todos por igual nos hace iguales y permite desafiar cualquier imposición; una igualdad que, también nos dice Diderot, desafía la misma idea, tan común en el XVIII, de un rey ilustrado pues «¿no puede ocurrir que la voluntad de este señor absoluto esté en contradicción con la voluntad de sus súbditos?» (p. 114). Y es que, en efecto, Diderot también aquí se explaya en hablar de la voluntad general como el punto que nos permite pasar de súbditos a ciudadanos -libres- y nadie sino el pueblo está legitimado a establecer tal voluntad general -«Pueblos, no consintais a vuestros presuntos dueños hacer tan siquiera el bien en contra de la voluntad general» (p. 26) - pues como se afirmará en el texto incluso el mejor de los principios es algo criminal si se afirma contra la voluntad de los ciudadanos (p. 115). Una voluntad que, añade Diderot en este tratado político, parte de una concepción del derecho natural que de alguna manera hace evidente lo que subyace al género humano, su dignidad. Para establecerla es verdad que se pueden utilizar diferentes aplicaciones, pero los principios siempre son constantes; en último término se trata de establecer una moral universal que «al atenerse a la naturaleza humana se atiene a la naturaleza de las sociedades; esta moral bien puede variar en sus aplicaciones, pero jamás en su esencia; esta moral es a la que todas las leyes deben rendir cuentas y subordinarse» (p. 77). Ley, voluntad general, derecho natural, tiene razón el editor al proponer que las propuestas de la modernidad política también se pueden reconstruir en las proposiciones políticas de Diderot; en este librito las encontramos con claridad, como también se distingue con claridad que todo ello reside en una concepción materialista de la naturaleza y del ser humano. Efectivamente, así comienza este libro: «Decís que hay una moral universal, y estoy de acuerdo con ello [...] ¿Dónde habría que buscar el origen de ese juicio unánime tan constante y tan generalizado en medio de opiniones contradictorias y efímeras? En una causa física constante y eterna. ¿Y dónde reside tal causa? En el propio ser humano, en la similitud de organización de uno a otro» (p. 21).

La naturaleza es homogénea y nada más que ella existe. Nosotros somos naturaleza y a ella debemos acudir para encontrar los principios de nuestras asociaciones que para ser justas deben ser naturales. Al igual que el buen salvaje no es objetable cuando sigue a la naturaleza y no la perpetra por mucho que su comportamiento nos parezca extraño, cruel o poco amable, la sociedad encuentra su modo óptimo de organización en un derecho natural, una moral natural que aquí se expresa con la misma voz de la naturaleza. Diderot concluye, o mejor, empapa su teoría política con un convencimiento que recuerda a Sade: los seres humanos, junto a sus conocimientos y conjeturas, ya sean acerca del pasado o proyectadas hacia el futuro, son el juguete de las leyes y movimientos de la naturaleza en su conjunto, la cual sigue su curso sin miramiento con respecto a nuestros proyectos y a nuestras acciones, e incluso a nuestra existencia, que no es sino una «secuela momentánea de un orden tan efímero como ella» (p. 233).

No es habitual leer a lo largo del libro de manera tan explícita este tipo de confesiones y Diderot se mueve más en la constatación simple de que cuanto más se alejan los hombres de la naturaleza más se alejan del movimiento justo y de la organización libre de sus movimientos, pero es aquí donde se funda su lucha contra el derecho de la religión a gobernar, su idea de que el Estado debe hacer residir su 
fuerza en sí mismo -establecido desde la voluntad general- y es aquí también donde fermentan algunas afirmaciones que recogiendo esa dependencia de la naturaleza ese vasallaje me atrevo a decir-concluyen que el conflicto, la lucha y el dinamismo y cambio de la naturaleza, nos es inevitable. Ello quizá ofenda un poco a nuestra democrática tranquilidad de espíritu - ¿más débil que la del salvaje? -, mas ya lo avisa el editor en su introducción: el conflicto, la lucha, la guerra no son ajenas a la política de Diderot quien no para mientes en afirmaciones de este tipo: «Los señores feudales fueron bestias feroces dignas de ser masacradas por sus vasallos» (p. 27) o «una nación no se regenera sino en un baño de sangre» (p. 84) o, por finalizar, «si sucede alguna dichosa revolución en el mundo, vendrá de América [...] pero hace falta que este cambio sea preparado por fermentaciones, sacudidas e incluso desgracias» ( $p$. 177). $Y$ es que, efectivamente, si uno mira a la naturaleza no verá sino cambios bruscos que inician nuevas eras; y si hemos apostado por la naturaleza no muy diferentes deberán ser los comienzos de los nuevos tiempos. Quizá este sea el Diderot menos amable, pero recuerdo la secuencia: ley que se establece desde una voluntad general que al fundamentarse en una moral natural es justa y no crea súbditos sino ciudadanos; esa moral natural debe ser la misma naturaleza que en no pocas ocasiones suele ser cruel. Es el final del camino del materialista y ello no tiene remedio ninguno.

Acordar las afirmaciones más liberales a favor de la propiedad privada, la libertad de prensa, o el derecho de los pueblos a independizarse o el comercio como elemento que finalizará los conflictos internacionales con estas últimas apuestas por el conflicto a imitación de la dinámica de la naturaleza, quizá no sea sencillo; lo cierto es que en este texto no encontraremos nunca que a Diderot ello le inquiete. Realmente, como ese viejo sabio que charla de todo con gracia y gusto, pero poco orden, Diderot habla de una cosa y otra sin darse cuenta de que debería detenerse y tratar de acordarlas. O dándose cuenta mas no concediéndole gran importancia. Por eso me permito diferir del editor: no se trata de avanzar con este librito un posible tratado de teoría política por parte de Diderot, sino que posiblemente es mejor entenderlo como una serie de propuestas políticas quizá no bien entrelazadas, pero tremendamente sugerente, y útiles. Repito: no hay aquí ningún tratado, pero ¿es ello preciso? ¿Acaso es más políticamente recomendable?

Miscelánea: De manera muy rápida no puedo dejar de anotar dos cuestiones que aparecen puntualmente en este libro y que hacen de Diderot alguien premonitorio o anticipador. La primera es su anuncio de que será la historia la materia hacia la que se volverán los espíritus para dar cuenta de los asuntos humanos (p. 235). La segunda aparece en el escueto y magnífico capítulo $V$, titulado "Sobre la guerra» en el que se concluye que «el hombre es el terrible azote del hombre. Si su anhelo secreto fuese satisfecho, pronto no quedaría más que uno solo sobre toda la superficie del globo» (p. 152). 